\title{
Exploring Teacher Attitude toward Information Technology with a Gender Perspective
}

\author{
Fatima Islahi \& Nasrin \\ Aligarh Muslim University, India
}

Submitted: 02.10.2017

Accepted: 09.10.2018

Published: 15.01.2019

\begin{abstract}
To acquire benefits from technology in education, due consideration must be given to attitude of teachers which plays an important role in guiding and predicting future successful use of technology in the classroom. With the feminization in the teaching fraternity and the studies reporting gender specific perception towards usefulness of technology and ease of use, the present study was, therefore, undertaken to examine the attitude of teachers towards use of technology in teaching with a gender perspective. A survey was conducted on 482 secondary school teachers from India, using Attitude towards Information Technology scale. The attitude of the respondents were assessed in terms of four dimensions; namely significance in life, usefulness for students, productivity for teaching, and teacher's interest and acceptance. The quantitative data were analyzed using appropriate statistical techniques like t-test and ANOVA. Findings suggest that with regard to different factors viz., training, location of schools, medium of instruction and marital status, no gender specific differences in attitude towards information technology was found. Based on these results, it can be concluded that the effective use of technology in classrooms should be expected from all teachers irrespective of their gender.
\end{abstract}

Keywords: Attitudes toward information technology; Gender differences; Teacher attitudes; ICT in the classroom

\section{Introduction}

Technological advances have significantly influenced the political, economic, social and educational arena across the globe. Presently, it has become an integral part of the education system, right from schools to universities. Researchers report technology based instructional applications as an effective alternative to traditional teaching methods, transforming the isolated, teacher centered, lecture based instruction and text bound classrooms into rich, student focused, interactive knowledge environments. On account of its recognized potential for learning support and development of learning skills, competencies and proficiencies (Hernández, 2017; Muralidharan, Niehaus, \& Sukhtankar 2017; Tarhin, Hone, \& Liu, 2015; Yilmaz, 2016), Information Technologies (ITs) have been directly or indirectly included in different plans and policies for education by governments of different countries.

India recognized the importance of IT in education as early as in 1984-85 when the Computer Literacy and Studies in Schools (CLASS) was introduced as a pilot project with the introduction of BBC micro-computers. Many more advanced schemes have been initiated and implemented since then but still the so-called technology revolution in schools never took place as expected, thereby making it a major concern to the education stakeholders of the nation. Research 
findings in the area of IT appear to be consistent, suggesting that in spite of the heavy investments on IT the educational advantages of it are still not adequately exploited by teachers (Ertmer \& Ottenbreit-Leftwich, 2010; Inan \& Lowther, 2010; Kim, Kim, Lee, Spector, \& DeMeester, 2013).

As the use of IT becomes more important in the educational setup, many studies have been conducted and identified factors that influence teachers' IT use. These include teachers' IT knowledge and skills (Eteokleous, 2008; Goktas, Gedik, \& Baydas, 2013; Hohlfeld, et al., 2008), inadequate training (Copley \& Ziviani, 2004) their motivation, workload and lack of time (Abuhmaid, 2011; Chigona, et al., 2014; Cullen \& Greene, 2011; Guoyuan, et al., 2011; Lee, 2011; Neyland, 2011; Slaouti \& Barton, 2007) anxiety (Buabeng-Andoh, 2012 ) teaching experience (Gorder, 2008; Wong \& Li, 2008) technology access, updated software and hardware (Plomp, et al., 2009; Slaouti \& Barton, 2007; Yildrim 2007) technical expertise and support (Chigona \& Chigona, 2010; Salehi \& Salehi, 2012; Yilmaz, 2011) etc. are some of the key elements identified for the successful adoption and integration of technology.

Amongst all these conditions, teacher's attitude towards Information Technology (ATIT) may play an important role in achieving success in its adoption, effective integration and utilization for positive output in education. Albirini (2006) points that successful implementation of information technologies in education depends on the attitude of the educators who finally decide how they are used in the teaching process. Attitudes influence not only initial acceptance, but also future behaviors. Jencius and Paez (2003) are of the opinion that understanding attitude is important because attitudinal barriers can hinder the adoption of new technology.

An important factor behind the resistance of the teachers in infusing the information technologies to education despite the facilities available in their schools and classrooms is their negative attitude towards technology (Lloyd \& Albion, 2005). They may see technology as threatening and overwhelming (Phelps \& Ellis, 2002) or fear looking foolish or incompetent in front of their students (Nunan \& Wong, 2005). This negative attitude can cause teachers to doubt the usefulness of IT in teaching and therefore disinclined to use technology in their teaching (Hennessy, Ruthven, \& Brindley, 2005). Past history has showed many promising technological innovations fail to attain their promises due to the negligence of the end-users' attitudes and needs (McCarthy, 1998).

It is assumed that positive disposition towards technology is a prerequisite for successful pedagogical use of technology as according to the Diffusion of Innovations Theory (Rogers, 1995), people's attitude towards a technology is one of the key elements to its adoption. On a similar note the Technology Acceptance Model (TAM) (Davis, 1989) also conveys the same message of having a positive attitude towards a technology before acceptance of the technology.

Appropriate use of IT cannot be accomplished without active involvement and support of teachers who are capable of exploiting the profound possibilities that IT can offer for the teaching-learning process. The level of success in its integration in schools is not dependent on quality or sophistication of the technology or by its sheer existence in the classroom but rather on the teachers' support and attitude (Bitner \& Bitner, 2002; Romano, 2003) and on the teachers' readiness and positive disposition (Deniz, 2007).

Because of their critical role in the implementation process, teachers' attitude towards IT should be the focus of studies at the early stages of technology implementation. Unfortunately, the 
zealous entry of technology into the schools and the subsequent change demands has little considered teachers' attitude (Harper, 1987). The result has often been obvious in teachers' passivity towards technology.

With the introduction of IT into education, a new dimension of "gender inequalities" has caught attention. This gender divide has emerged along the lines of previously existing social divides. The orthodox and conventional gender disparities that existed in science related subjects have been extrapolated into IT. Over the years, a stereotypical view concerning technology use and gender has been developed, which is, relative to men and boys, women and girls might have more negative attitude towards technology and technology use, and they would be less actively engaged in technology-related activities and behaviors. Society views technology as highly technical and part of a male domain and use of IT tools perceived as a masculine activity (North \& Noyes, 2002).

Research has described a variety of ways in which women lag behind men in the ownership of technology and the development of technological skills. For example, men own and use technology more than women, spend more time online, take more technology classes, and show more motivation to learn digital skills (Cooper, 2006; Correa, 2010; Fallows, 2005; Livingstone \& Helsper, 2007; Pinkard, 2005; Tezci, E., 2009). They have more experience and make more use of Internet than women for a wide range of activities, particularly those that require greater technological skills such as job searching, e-banking, and posting or uploading material (Fallows, 2005; Hargittai \& Walejko, 2008). There is a tendency to find greater anxiety among the females than males about technology use (Durndell \& Haag, 2002; Schottenbauer et al., 2004). Studies have suggested that the masculine image of the computer has deterred females from benefiting from the technology and this has made them less confident or more anxious (Culley, 1988). Also the social image that computer scientists are geeks, nerds, or socially isolated people and the perception that computer science is for males, seem to have an influence on the girls' negative attitude towards computers (Sainz \& Lopez-Saez, 2010).

According to Males Giddens' structuration theory (1984) even as individuals have the agency to pursue their desires, social structures can influence their behaviors and the way they think about objects such as technology. There are also cultural and psychological factors that may constrain certain people, such as women, from using technologies even when they have access (Terry \& Gomez, 2010).

Some research report that, although there has been evidence of increased participation by girls in the technology-related tasks, boys remained to show more interest and more enjoyment than girls (Colley \& Comber, 2003) in technology use. Such factors are anticipated to be more prominent in traditional societies like India. In recent years, there has been a growing interest in studying the gender groups' attitude towards technology (Ardies, Maeyer, \& Gijbels, 2015; Potvin \& Hasni, 2014; Teo, Milutinovic, \& Zhou, 2016). But the research findings from various individual studies about gender difference, or lack thereof, in the attitude toward technology use have been inconsistent, making it difficult to draw any firm conclusion.

Moreover, most research on gender differences of IT usage has been done in western countries (Li \& Kirkup, 2007). Since gender is a social construct determined by cultural, social, and economic factors and differ within and between cultures and countries, one cannot presume that it will be expressed in the same way everywhere. The varying customs, beliefs, prejudices, norms, expectations and stereotypes of the society about what is appropriate for both genders is bound to have a varying affect on men and women of different societies. 
It is also plausible that people from different regions may have different understanding about technology use as a result of uneven economic development levels and differences in the accessibility of technology. Such factors may lead to differences in terms of how gender groups view technology use in different cultural contexts. Therefore, studies of gender differences in attitude toward IT usage in different cultural contexts need to be carried out. Gender is of interest to the general populace especially now that females are gradually taking over and dominating the teaching profession.

In an attempt to encourage women's education, early post-independence policy documents in India from 1947 onwards all stressed the need to recruit female teachers, and included recommendations to incentivize female teachers. Suggestions included giving female teacher preference when admitting recruits into teacher training institutions, giving female teachers from rural areas greater preference, and providing female teachers posted to rural areas with living quarters and a special allowance. These policy recommendations were further supplemented by quotas of at least half of all teachers appointed to be female in certain situations, and the setting up of exclusively girls' schools and colleges where most teachers would be female, teacher training centers exclusively for women and incentives for female teachers who work in remote areas.

In some cases, as a temporary solution, expeditious recruitment drives are carried out where young women are fast-tracked into teacher education. In addition to government policies, societal beliefs and practices have also tended to support the entry of women into teaching. Amongst the middle classes, teaching is viewed as a suitable profession for women because it is seen to be less demanding, (having shorter hours than many other jobs) and therefore compatible with household and childcare responsibilities.

This targeted female recruitment drives along with societal support to women teachers has led to feminization of teaching profession. The term 'feminization' has been used by sociologists and educators where the participation of women in a certain occupation is increasing. The Working Group of the European Trade Union Committee for Education (ETUCE) used the term feminization to "describe the phenomenon of large-scale entry into the teaching profession by women ..." (Wylie, 2000). This has led researchers to debate about the impact of feminization on learning processes and educational outcomes especially when on one hand the exponential advances in technology and their rapid integration in the education system has created opportunities for teachers to exploit a new tool to attain their objectives more efficiently and on the other men are stereotypically considered as more competent than women in technology and innovation. Such a stereotype may also increase women's levels of anxiety and affect their performance (Cooper, 2006; Meraz, 2008). With this background, the question arises that "can the blame be put on feminization of teaching profession for the not so-successful implementation of IT into educational systems?"

Published literature from India, shows sparse availability of studies on the aspect. In the present context, it becomes necessary to explore attitude of teachers towards IT with a gender perspective with reference to various demographic factors. Therefore, the purpose of this study was to find answers for the following research questions:

(1) Does attitude towards information technology differ with respect to gender?

(2) Do factors like training, location of schools, medium of instruction and marital status have a gender biased influence on teachers' attitude towards information technology? 


\section{Methodology}

The present study was descriptive in nature. Target population of the study comprised of secondary school teachers from Aligarh city of Uttar Pradesh, India and its adjoining areas. A sample of 482 teachers including 245 (50.88\%) males and 237 (49.17\%) females working in 30 different secondary schools was drawn from the target population by purposive convenient sampling technique. Only those teachers who had some experience of information technology were chosen. By information technology here it is essentially meant as computers and internet which help in acquisition, organization, processing, storage and dissemination of information. Since the study intended to look into the gender difference, care was taken that a proper representation of male and female teachers was there. The age of the participants ranged from 22 to 60 years. The participants had 1 to 38 years of teaching experience in schools.

The background factors considered in the study were gender, location, training, medium of instruction and marital status. The variable of attitude was determined by Likert based five-point (strongly disagree, disagree, no idea, agree, and strongly agree) self-rating Attitude towards Information Technology (ATIT) scale developed by Nasrin and Islahi (2011). The scale comprised 30 items with 18 positive statements and 12 negative statements. The scale aimed to evaluate teachers' attitude toward information technology in the areas of (i) significance in life (7 items) which had items like "I see the use of information technology rarely in my daily life.", (ii) usefulness for student (7 items) which had items like "Use of information technology motivates the pupils to learn.", (iii) productivity for teaching ( 7 items) which had items like "Information technology for my teaching is worthless.", and (iv) teacher's interest and acceptance (9 items) which had items like "I would like to learn more about the use of IT in making my teaching effective.". The reliability for the scale (30 items) was established at 0.89 by Cronbach alpha, indicating good internal consistency. The scale was validated for its face and content validity by a panel of three experts at Aligarh Muslim University.

English as well as Hindi versions of the scale were administered along with a cover letter explaining the purpose of the survey and detailed instructions to fill up the scale. Each teacher was to respond by reacting to the statement based on the five-point ATIT Scale and put a tick mark in appropriate boxes given against the items with which he/she agreed. There was no option to leave any item unanswered. The lower scores on the attitude scale indicated negative attitude of teachers towards IT and vice-versa.

The scale was distributed to the teachers of secondary level in different schools after the approval of their management. The participants were introduced with main objectives of the study and requested to read the instructions carefully and ask the researcher if there was any difficulty in understanding the instructions. It was emphasized that no item should be omitted and that there were no correct or incorrect answers. Also, there was no time limit for the scale and it was not necessary to answer all of the items during one session. The raw scores were reorganized, subjected to appropriate statistical analysis and summarized. This was achieved by using the SPSS version 12.0 statistical package.

By convention, an alpha level of .05 was established a priori for determining statistical significance. Each item was assigned a weightage ranging from 5 (strongly agree) to 1 (strong disagree) for favorable items. In case of unfavorable items, the scoring was reversed, i.e. from 1 (strongly agree) to 5 (strongly disagree). The attitude score of an individual is the sum total of item scores on all the four areas. The range of scores is from 30 to 150 with the higher score 
indicating the more positive attitude and vice-versa. Prior to conducting the analysis, the scoring of all negatively stated items was reversed.

\section{Results}

The study sought information on teacher demographic characteristics to help in classifying them and further use the data to establish the relationship between the demographic characteristics with respect to gender and their attitude towards information technology. The data obtained from the teachers are summarized in Table 1.

Table 1. Descriptive Statistics of Demographic Variables for Attitude towards Information Technology

\begin{tabular}{llcccc}
\hline Variables & Categories & $\mathrm{N}$ & $\%$ & Mean & SD \\
\hline Gender & Male & 245 & 50.8 & 98.13 & 24.021 \\
\multirow{3}{*}{ Location } & Female & 237 & 49.2 & 94.58 & 22.136 \\
& Rural & 244 & 50.6 & 92.64 & 23.113 \\
Training & Urban & 238 & 49.4 & 100.22 & 22.615 \\
& Trained & 291 & 60.4 & 98.02 & 23.657 \\
Medium of instruction & Untrained & 191 & 39.6 & 93.89 & 22.203 \\
& Hindi & 238 & 49.4 & 90.41 & 22.348 \\
Marital status & English & 244 & 50.6 & 102.21 & 22.479 \\
& Married & 319 & 66.2 & 91.97 & 22.513 \\
& Unmarried & 163 & 33.8 & 105.01 & 22.004 \\
\hline
\end{tabular}

In order to understand the difference in attitude towards information technology with respect to gender, the overall attitude scores of male and female teachers were subjected to independent-samples t-test (see Table 2). Though male participants recorded slightly higher mean scores $(M=98.13, S D=24.021)$ than females $(M=94.58, S D=22.136)$, there was no significant difference $t(480)=1.68, p>0.05$ between attitude of male and female teachers.

Table 2. Difference in Attitude of Male and Female Teachers

\begin{tabular}{lccccccc}
\hline & $\mathrm{N}$ & Mean & SD & SEM & df & $t$ & $\mathrm{p}$ \\
\hline Male & 245 & 98.13 & 24.021 & 1.535 & \multirow{2}{*}{480} & \multirow{2}{*}{1.68} & \multirow{2}{*}{0.093} \\
Female & 237 & 94.58 & 22.136 & 1.438 & & & \\
\hline
\end{tabular}

Attitude towards IT was measured in terms of (i) significance in life, (ii) usefulness for students, (iii) productivity for teaching, and (iv) teacher's interest and acceptance. All 482 participants responded to all items in the ATIT scale and no missing data was found in the survey. Table 3 presents the participants' mean scores. The overall attitude $(M=96.38)$ is above the mid-point of the range of scores (30 to 150) on the scale and this indicated that participants held somewhat positive attitude towards IT. The participants scored the lowest on the teachers 'Productivity for teaching' ( $M=22.54, S D=6.47)$ followed by the 'Usefulness for students' subscale $(M=22.66$, 
$S D=6.89)$ and 'Significance in life' subscale $(M=22.69, S D=6.22)$. The highest mean score was for the 'Interest and Acceptance' subscale ( $M=28.50, S D=7.71)$. The means suggest that while the participants were having an interest in information and technology and were more acceptable but comparatively did not find IT useful for their teaching or for their students. The findings, when analyzed gender wise, showed that female teachers were more skeptical across all the domains than male teachers; however, the $t$ values established that the obvious differences in the means were insignificant.

Table 3. Difference in Attitude of Male and Female Teachers with Respect to Sub-domains of the Scale

\begin{tabular}{lccccc}
\hline Factors & Overall mean & Male mean & Female mean & $\mathrm{t}$ & $\mathrm{p}$ \\
\hline Significance in life & 22.69 & 23.04 & 22.33 & 1.24 & 0.215 \\
Usefulness for students & 22.66 & 23.09 & 22.22 & 1.39 & 0.166 \\
Productivity for teaching & 22.54 & 23.04 & 22.02 & 1.73 & 0.084 \\
Interest and Acceptance & 28.50 & 28.97 & 28.02 & 1.35 & 0.176 \\
\hline
\end{tabular}

The variables (location, training, medium of instruction and marital status) were assumed to influence the attitude toward information technology with respect to gender. One-way ANOVA of the average attitude scores of male and female teachers with respect to their location (rural/urban) have been presented in Table 4. Results revealed that there was a significant difference $[F(3,478)=5.496, p<0.05]$ in the attitude of the groups: rural male, urban male, rural female and urban female teachers. Tukey's post hoc test for significance indicated that the urban teachers irrespective of their gender had a more positive attitude towards IT than those who belonged to the rural areas.

Table 4. Difference in Attitude of Male and Female Teachers with Respect to Their Location

\begin{tabular}{lccc}
\hline \multirow{2}{*}{ Factors } & $\mathrm{N}$ & \multicolumn{2}{c}{${ }^{*}$ Subset of Means for alpha $=.05$} \\
\cline { 3 - 4 } & & 1 & 2 \\
\hline Rural Female & 49 & 90.37 & \\
Rural Male & 42 & 94.77 & 98.76 \\
Urban Female & 71 & & 101.68 \\
Urban Male & 83 & &
\end{tabular}

*Means in the same column are insignificantly different from each other.

Results of the attitude scores of male and female teachers with respect to their training (that is one who has successfully undergone a course of training in teaching through a recognized teacher training institution) have been presented in Table 5. The ANOVA results revealed that the ATIT scores of different category teachers (untrained male, untrained female, trained male and trained female) were insignificantly different $[F(3,478)=2.181, p>0.05]$ from each other.

Table 5. Difference in Attitude of Male and Female Teachers with Respect to Their Training

\begin{tabular}{lccccc}
\hline & Sum of Squares & $\mathrm{df}$ & Mean Square & $\mathrm{F}$ & $\mathrm{p}$ \\
\hline Between Groups & 3483.537 & 3 & 1161.179 & & \\
Within Groups & 254456.457 & 478 & 532.336 & 2.181 & 0.089 \\
Total & 257939.994 & 481 & & & \\
\hline
\end{tabular}

Average attitude scores of male and female teachers with respect to their medium of instruction (Hindi/English) were found to be significantly different $[F(3,478)=12.930, p<0.05]$ (see Table 
6). Multiple comparison test using the Tukey's post hoc criterion for significance indicated that the English medium school teachers irrespective of their gender had a more positive attitude towards IT than those teachers who belonged to Hindi medium schools.

Table 6. Difference in Attitude of Male and Female Teachers with Respect to Their Medium of Instruction

\begin{tabular}{llcc}
\hline & $N$ & \multicolumn{2}{c}{ *Subset of Means for alpha $=.05$} \\
\cline { 3 - 4 } Factors & 49 & 1 & 2 \\
\cline { 3 - 4 } Hindi Medium Female & 42 & 90.78 & \\
Hindi Medium Male & 71 & 91.17 & 101.90 \\
English Medium Female & 83 & & 106.70 \\
English Medium Male & &
\end{tabular}

*Means in the same column are insignificantly different from each other.

One-way ANOVA of the average attitude scores of male and female teachers with respect to their marital status (married/unmarried) revealed that there were significant differences [ $\mathrm{F}$ $(3,478)=14.431, p<0.05]$ in ATIT scores of the four groups (Table 7). A post hoc analysis using Tukey's procedure further revealed that lowest ATIT values observed for married female teachers were comparable to those obtained for married male teachers but significantly different from unmarried male and unmarried female teachers. Highest ATIT values observed for unmarried female teachers were comparable to those obtained for unmarried male teachers.

Table 7. Difference in Attitude of Male and Female Teachers with Respect to Their Marital Status

\begin{tabular}{llcc}
\hline Factors & $\mathrm{N}$ & \multicolumn{2}{c}{ *Subset of Means for alpha $=.05$} \\
\cline { 3 - 4 } & & 1 & 2 \\
\cline { 3 - 4 } Married Female & 74 & 89.02 & \\
Married Male & 51 & 94.98 & 103.84 \\
Unmarried Male & 37 & & 106.36 \\
Unmarried Female & & &
\end{tabular}

*Means in the same column are insignificantly different from each other.

\section{Discussion}

This study intended to better understand existing attitudes toward information technology on part of the teachers - the principal users of technology in the classrooms. While most of the existing studies have examined attitude towards technology for pedagogical purposes, typically in the context of developed countries, this study has tried to fill a research gap by investigating whether gender difference in attitude towards technology exists within a community of developing country, and how it varies when different factors are taken into consideration. The insignificant difference in attitude of male and female teachers observed in this study was in contrast with the earlier studies wherein females exhibited more negative views and perceptions towards the use of computers than males (Dupagne \& Krendi, 1992; Kay, 1992; Koohang, 1987; Wozney et al., 2006). This gender difference in technology is believed to have been partly developed by the influence of society's perception on what is appropriate for each gender. The gender role is so clearly defined that even young children tend to demonstrate some gender specific behaviors and seem to accept the idea that girls and boys are supposed to 
behave differently (Bhargava, et al., 1999). Women seem to think that they are not supposed to be good at using IT and that men know much more about them. It has also been reported that men overestimate their abilities and performance, while women underestimate both even though their actual performance does not differ in quality or quantity.

However, in this study, non-significant difference in attitude towards IT between genders is consistent with the studies that show that gender differences no longer exist (Bakr, 2011; Gujjar et al., 2013; Khan, 2013; Rajpoot \& Rajpoot, 2011; Sainz, et al., 2016; Wong \& Hanafi, 2007; Yusuf, 2011). Numerous studies are now reporting females' attitude towards technology is similar to that of males. They appear to be more comfortable when using technology than before and this may have resulted in decreasing the barriers perceived by them. The difference in attitude earlier can be presumed to be basically because males had greater exposure to technology both in formal instructional settings and informal settings. However, with rapid development and infiltration of technology in every aspect of the society to the point that technology has become an indispensable part of our daily lives, may have had an effect of equalizing difference between males and females. The contemporary male teachers may no longer have an edge over their female counterpart in their attitude to IT use.

Kirkpatrick and Cuban (1998) noted that the gender gap was narrowed when both genders were exposed to the same amounts and types of experiences when using computers. This opinion is also supported by Kay (2006) and Koh, Chai and Tsai, (2010). Recent research - especially within the TAM framework - conclude that the TAM holds for both women and men (Teo et al., 2015). The popularity of social networking sites and the increased number of household with internet have played a role in how technology is being used today. The current trend of no significant differences in attitude levels based on gender, as opposed to the eighties and nineties may be attributed to equal interaction of both the sexes with technology. Therefore, it can be stated that whatever the differences arising from the new technology related attitude and usage conditions are caused by the social gender roles and the early chance of men to have more experience in these technologies rather than by the inherent gender characteristics.

Attitude towards IT was measured in terms of (i) significance in life, (ii) usefulness for students, (iii) productivity for teaching, and (iv) teacher's interest and acceptance. The participants scored the lowest on the teachers 'Productivity for teaching' followed by the 'Usefulness for students' subscale and 'Significance in life' subscale. The results suggest that while the participants were having an interest in information and technology and were more acceptable but comparatively did not find IT useful for their teaching or for their students. This should be a matter of concern for educationists and policy makers as to why the teachers in spite of being more acceptable towards technology do not find it useful in its practical application in the educational setup and should be further researched.

When different demographic factors were taken into consideration, trained and untrained teachers exhibited similar ATIT. As discussed above, the availability and accessibility of technological resources and experience with it during their training in teaching through a recognized teacher training institution could have lead teachers to gain competence and confidence in using IT resources and developing a positive attitude irrespective of their gender. This is in line with the old theory of Zajonc (1968) that the more a person is exposed to an object or a person, the more he or she responds positively to that object or person.

Attitude towards IT was found to be significantly influenced by geographical location (rural and urban). Urban school teachers exhibiting a significantly positive ATIT is in corroboration with the 
findings of various other studies (Li, 2012; Zaman et al., 2018; Zhao, Xu, \& Chen, 2017). This could be attributed to the challenges related to school funding, lack of availability and accessibility of technological resources (Kumar \& Kumara, 2018), capacity for maintaining equipment and infrastructure along with disciplinary problems in schools situated in rural areas as compared to urban areas that can make technologically mediated instruction more laborintensive, than other instructional approaches. Furthermore, irregular and interrupted power supply (Kumar \& Kumara, 2018), slow bandwidth, slower internet speeds in rural areas may also happen to be major deterrents in adoption of technology. Research by market services firm Kantar-IMRB and the Internet and Mobile Association of India (IAMAI) found that by the end of 2017 internet penetration in urban India was at $65 \%$ as compared to $20 \%$ in rural India. This disparity is an obvious indication of why a gap exists in ATIT of rural and urban teachers.

Interestingly, ATIT was significantly influenced by medium of instruction irrespective of gender, which suggests that regardless of their gender teachers of English medium schools had a significantly more positive attitude towards IT than teachers of Hindi medium schools. This may be due to the fact that the limited technological resources and expertise available in Hindi medium schools could have hindered the teachers in acquiring ATIT as positively as English medium school teachers. Nevertheless, this trend is in contrast with previous studies that reported no significant differences in ATIT of Hindi and English medium school teachers (Khan, 2013; Sharma, 2013).

Similarly, marital status was found to have a significant influence on ATIT irrespective of gender. Unmarried teachers had a more positive outlook towards IT than married teachers. On the contrary, Rajpoot and Rajpoot (2011) reported no significant differences in ATIT between the married and unmarried teachers. The results of this study may be explained by assuming that married teachers were older than unmarried teachers, the average age of unmarried teachers being (33) and that of married teachers being (42) years. Since technology availability, exposure and uptake is usually more among the younger generation so the ATIT of unmarried teachers was more positive than married teachers.

In this context, Jennings and Onwuegbuzie (2001) observed a more positive attitude towards the use of ICT in younger teaching staff. Similarly, Hernes et al., (2000) concluded that the teaching staff that showed a good command on the use of the Internet are negatively correlated with age. They observed that around $63 \%$ of the teaching staff who are 25 years or younger versus only $32 \%$ of the teachers who are 56 years or older have a positive attitude towards the use of the Internet in their own teaching. This is also consistent with existing research that found older teachers to be less positive toward technologies, and were incorporating technology in teaching to a lesser degree (Athina \& George 2005; Cavas et al. 2009; Jennings \& Onwuegbuzie, 2001; Kuskaya-Mumcu \& Kocak-Usluel 2010).

Although current research demonstrates that technology adoption in education has less to do with age (Bullen, Morgan, \& Qayyum, 2011; Guo, Dobson, \& Petrina, 2008; Helsper \& Eynon, 2010), it might be possible that the work-family conflict in case of married teachers could have contributed to the present findings of the study. After marriage, an individual has to balance his/her duties at home and at work thereby dividing the time and energy between the two. Madhavi and Vimala (2011) infer from their study that employees in the age group 25-35 years are found to have more work family issues than other age groups. Work-family issues among such women may be due to more commitment in the organizational roles and family roles. The conflict resulting because of simultaneous pressures from work and family roles seem to be mutually incompatible. Such conflicting demand is likely to threaten the peace of mind, quality 
of work and eventually leaves little time for them to go for technological innovation and have a positive attitude towards it.

\section{Conclusion}

In sum, this study revealed that teachers irrespective of their gender have a positive attitude towards technology. Teachers perceive technology of immense significance in life with usefulness for students and productivity for their teaching. They have interest in adopting and accepting IT in the educational setup. The increased use of IT in teaching and learning at schools has shrunk the gender differences among teachers' attitude towards IT. Therefore, it can be stated that whatever the differences arising in attitude and usage conditions are socially constructed and the early chance of men to have more experience in these technologies rather than by the innate gender characteristics or ability. The availability of computers at home also affects the attitudes towards it use in classroom. Those who have computer at home have positive attitude towards its use in classroom as compared to those who lack this facility at home (Isman \& Dabaj, 2004). Thus, it is suggested that educational institutions should set up training programs for teachers so that they are made aware of the different innovative techniques and methods which can help develop a positive attitude in using and integrating technology. These training programs must be added, removed or revised, as new technologies evolve.

The technology training courses need not have a women-oriented or male-oriented approach but a human-centric approach to blossom and yield more productive results. By providing information to teachers on new technological developments and their application can help them develop more positive attitudes towards technology and thus increase the quality of education through more active and effective use of technologies concerning education and training.

According to Bandura (1999), the socio cognitive theory recognizes the influence of environment and observational learning on human adaptation and change. Assuming gender as an important predictor of abilities, skills and interests of an individual is erroneous. Such ways of categorizing gender often lead to gender hierarchies and injustices for whole groups as well as individuals (Connell, 2002). While there may be broad gender trends, these are trends only; they should not be interpreted as generalized rules. Any differences exhibited should be regarded as some cultural, societal or situational influences and experiences of the genders, which should be further investigated and used synergistically to improve professional service. It seems clear that effective use of technology in classrooms should be expected from all teachers irrespective of their gender in the future and positive attitudes towards IT alone is not sufficient for effective integration of technology, but an indication that teachers are willing to take-up technology. Therefore, efforts should be directed towards their updated training and continuous support to incorporate IT into their teaching.

\section{Limitations and Recommendations}

Although the analyses presented reveal some interesting findings, it is acknowledged that the methodological limitations and future research need to be addressed and discussed. One limitation of the study on which the arguments are based was its sample, which included only teachers of secondary schools of Aligarh. As the study is geographically bounded, this imposes a limitation on the generalizability of the findings. Hence, it is recommended that more research be undertaken with bigger and more diverse samples across the country. 
Another limitation was that the self-reported survey had been employed to assess attitude of secondary school teachers although there are a variety of other criteria available for the purpose. Self-report instruments may have several limitations such responding inconsistently or in a socially desirable manner. Therefore, alternative and multiple measures need to be used (Dursun, Donmez, \& Akbulut, 2018). Studies should be conducted employing mixed methods of data collection. Additional qualitative techniques, such as interviews and focus groups, could be used to explore if any differences exist in the way women and men relate to technology and if variations appear in their pattern of handling and usage of technology.

This study provides a glimpse of selected variables that were assumed to affect the attitudes of teachers towards technology. Future studies could include a systematic examination of other aspects and how these interact to impact on teachers' attitudes, acceptance, and extent of usage of technology as a tool for instructional purposes and professional development.

Because the findings from this study confirm that gender has little impact on teachers' attitudes, future studies should focus more on the development of effective models and frameworks in the learning and implementation of instructional and assessment technologies.

\section{References}

Abuhmaid, A. (2011). ICT Training Courses for Teacher Professional Development in Jordan. The Turkish Online Journal of Educational Technology, 10(4), 195-210.

Albirini, A. (2006). Teachers' attitudes toward information and communication technologies: The case of Syrian EFL teachers. Computers \& Education, 47, 373-398.

Ardies, J., De Maeyer, S., \& Gijbels, D. 2013. Reconstructing the Pupils Attitude towards Technology-survey. Design and Technology Education: An International Journal, 18 (1), 8-19.

Athina, M. \& George, H. (2005). Pedagogical obstacles in teacher training in information and communication technology. Technology, Pedagogy and Education, 14(2), 241-254.

Bakr, S. M. (2011). Attitudes of Egyptian teachers towards computers, Contemporary Education Technology, 2(4), 308-318.

Bandura, A. 1999. Social cognitive theory of personality. In L. Pervin \& O. John (Eds.), Handbook of personality (2nd edition). New York: Guilford.

Bhargava, A., Kirova-Petrova, A., \& McNair, S. (1999). Computers, gender bias, and young children. Information Technology in Childhood Education,1999 (1), 263-274.

Bitner, N. \& Bitner, J. (2002). Integrating technology into the classroom: eight keys to success. Journal of Technology and Teacher Education, 10(1), 95-100.

Buabeng-Andoh, C. (2012). Factors Influencing Teachers' Adoption and Integration of Information and Communication Technology into Teaching: A Review of the Literature. International Journal of Education and Development using Information and Communication Technology, 8(1), 136-155.

Bullen, M., Morgan, T. \& Qayyum, A. (2011). Digital learners in higher education: generation is not the issue. Canadian Journal of Learning \& Technology, 37(1), 1-24. 
Cai, Z., Fan, X., and Du, J. (2017). Gender and attitudes to- ward technology use: A metaanalysis. Computers \& Education, 105, 1-13. https://doi.org/10.1016/j.compedu. 2016.11.003

Cavas, B., Cavas, P., Karaoglan, B., \& Kisla T. (2009). A study on science teachers' attitudes toward information and communication technologies in education. The Turkish Online Journal of Educational Technology, 8(2), 20-32.

Chigona, A. \& Chigona, W. (2010). Capability approach on pedagogical use of ICT in schools. TD: The Journal for Transdisciplinary Research in Southern Africa, 6(1), 209-224. doi:http://hdl.handle.net/10394/3617

Chigona, A., Chigona, W., \& Davids, Z. (2014). Educators' motivation on integration of ICTs into pedagogy: Case of disadvantaged areas. South African Journal of Education, 34(3), 01-08.

Colley, A. \& Comber, C. (2003). Age and gender differences in computer use and attitudes among secondary school students: What has changed? Education Research, 45(2), 155165.

Connell, R. (2002). Gender: Short introductions. Cambridge: Polity.

Cooper, J. (2006). The digital divide: The special case of gender. Journal of Computer Assisted Learning, 22(5), 320-334.

Copley J. \& Ziviani, J. (2004). Barriers to utilisation of assistive technology with children who have multiple disabilities. Occupational Therapy International, 11(4), 229-43.

Correa, T. (2010). The participation divide among "online experts": Experience, skills, and psychological factors as predictors of college students' web content creation. Journal of Computer-Mediated Communication, 16(1), 71-92.

Cullen, T. A. \& Greene, B. A. (2011). Preservice teachers' beliefs, attitudes, and motivation about technology integration. Journal of Educational Computing Research, 45(1), $29-47$.

Culley, L. (1988). Option choices and careers guidance: Gender and computing in secondary schools. British Journal of Counseling and Guidance, 16(1), 72-82.

Davis, F. D. (1989). Perceived usefulness, perceived ease of use, and user acceptance of information technology. MIS Quarterly, 13(3), 319-340, doi:10.2307/249008

Deniz, L. (2007). Prospective class teachers' computer experience and computer attitude. International Journal of Social Sciences, 2(2), 116-122.

Durndell, A. \& Haag, Z. (2002). Computer self-efficacy, computer anxiety, attitudes towards the Internet and reported experience with the Internet, by gender, in an East European sample. Computers in Human Behavior, 18(5), 521-535. http://dx.doi.org/10.1016/ S0747-5632(02)00006-7

Dursun, O. O., Donmez, O., \& Akbulut, Y. (2018). Predictors of cyberloafing among preservice information technology teachers. Contemporary Educational Technology, 9(1), 22-41.

Ertmer, P. A. \& Ottenbreit-Leftwich, A. T. (2010). Teacher technology change: How knowledge, confidence, beliefs, and culture intersect. Journal of Research on Technology in Education, 42(3), 255-284.

Eteokleous, N. (2008). Evaluating computer technology integration in a centralized school system. Computers \& Education, 51(2), 669-686. doi:10.1016/j.compedu.2007.07.004 
Fallows, D. (2005). How men and women use the Internet. Pew Internet and American Life Project. Retrieved on from 01 October 2017 http://www.pewlnternet.org/Reports/ 2005/How-Women-and-Men-Use-the-Internet.aspx

Goktas, Y., Gedik, N., \& Baydas, O. (2013). Enablers and barriers to the use of ICT in primary schools in Turkey: A comparative study of 2005-2011. Computers \& Education, 68, 211222. doi:10.1016/j.compedu.2013.05.002

Gorder, L. M. (2008). A study of teachers' perceptions of technology integration in the classroom. The Delta Pi Epsilon Journal, 50(2), 63-76.

Gujjar, A. A., Naemullah, M., \& Tabassum, R. (2013). A study of the attitudes of student teachers toward use of computer. Pakistan Journal of Commerce and Social Sciences, 7(2), 346-353

Guo, R. X., Dobson, T. \& Petrina, S. (2008). Digital natives, digital immigrants: An analysis of age and ICT competency in teacher education. Journal of Educational Computing Research, 38(3), 235-254

Guoyuan, S., Valcke, M., van Braak, J., Tondeur, J., \& Zhu, C. (2011). Predicting ICT integration into classroom teaching in Chinese primary schools: Exploring the complex interplay of teacher-related variables. Journal of Computer Assisted Learning, 27(2), 160-172. doi:10.1111/j.1365-2729.2010.00383.x

Hargittai, E. \& Walejko, G. (2008). The participation divide: Content creation and sharing in the digital age. Information, Communication \& Society, 11(2), 239-256.

Harper, D. O. (1987). The creation and development of educational computer technology. In R. M. Thomas \& V. N. Kobayashi (Eds.), Educational Technology-Its creation, development and cross-cultural transfer (pp.35-64). Oxford: Pergamon.

Helsper, E. J. \& Eynon, R. (2010). Digital natives: Where is the evidence? British Educational Research Journal, 36(3), 503-520

Hennessy, S., Ruthven, K., \& Brindley, S. (2005). Teacher perspectives on integrating ICT into subject teaching: Commitment, constraints, caution, and change. Journal of Curriculum Studies, 37(2), 155-192.

Hernández, R. (2017). Impact of ICT on Education: Challenges and Perspectives. Journal of Educational Psychology - Propósitos y Representaciones, 5(1), 337-347.

Hernes, F. et al., (2000). Knowledge and competence in ICT among teachers in Norway. Retrieved on 15 October 2011 from http://www.ifip.or.at/con2000/iceut2000/iceut0904.pdf

Hohlfeld, T.N., Ritzhaupt, A.D., Barron, A.E., \& Kemker, K. (2008). Examining the digital divide in K-12 public schools: Four-year trends for supporting ICT literacy in Florida. Computers \& Education, 51(4), 1648-1663. doi:10.1016/j.compedu.2008.04.002

Hohlfeld, T. N., Ritzhaupt, A. D., Barron, A. E., \& Kemker, K. (2008). Examining the digital divide in K-12 public schools: Four-year trends for supporting ICT literacy in Florida. Computers \& Education, 51(4), 1648-1663.

https://www.computer.org/csdl/proceedings/iset/2017/3031/00/08005405.pdf

Inan, F. \& Lowther, D. (2010). Factors affecting technology integration in K-12 classrooms: A path model. Educational Technology Research and Development, 58(2), 137-154. 
Isman, A. \& Dabaj, F. (2004). Attitudes of students towards Internet. Turkish Online Journal of Distance Education, 5(4). Retrieved on 01 October 2017 from http://tojde.anadolu.edu. tr/tojde16/articles/dabaj.htm

Jancius, M. \& Paez, S. (2003). Converting counselor Ludites: Winning over technology resistant counselors. In J. W. Bloom \& G. R. Walz (Eds.), Cybercounseling and cyberlearning: Strategies and resources for the millennium (pp 81-114) Alexandria, VA: American Counseling Association.

Jennings, S. \& Onwuegbuzie, A. (2001). Computer attitudes as a function of age, gender, math attitude, and developmental status. Journal of Educational Computing Research, 25(4), 367-384.

Kay, R. H. (1992). An analysis of methods used to examine gender differences in computerrelated behaviour. Journal of Educational Computing Research, 8(3), 323-336.

Kay, R. (2006). Addressing gender differences in computer ability, attitudes and use: The laptop effect. Journal of Educational Computing Research, 34(2), 187-211.

Khan, S.H. (2013). Attitude of prospective teachers and prospective teacher educators' towards the usage of information and communication technology and its related technologies in colleges of teacher education. Scholarly Research Journal for Interdisciplinary Studies, 2(8), 368-381.

Kim, C., Kim, M.K., Lee, C., Spector, J.M., \& DeMeester, K. (2013). Teacher beliefs and technology integration. Teaching and Teacher Education, 29, 76-85. doi: 10.1016/j. tate.2012.08.005

Kirkpatrick, H. \& Cuban, L. (1998). What the research says about gender differences in access, use, attitudes and achievement with computers. Educational Technology, 38(4), 56-61.

Koh, J. H. L., Chai, C. S., \& Tsai, C. C. (2010). Examining the technological pedagogical content knowledge of Singapore pre-service teachers with a large-scale survey. Journal of Computer Assisted Learning, 26(6), 563-573.

Kumar, B.T. S. \& Kumara, S.U.S. (2018). The digital divide in India: Use and non-use of ICT by rural and urban students. World Journal of Science, Technology and Sustainable Development, 15(2), 156-168. https://doi.org/10.1108/WJSTSD-07-2017-0021

Kuskaya-Mumcu, F. \& Kocak-Usluel, Y. (2010). ICT in vocational and technical schools: Teachers' instructional, managerial and personal use matters. Turkish Online Journal of Educational Technology, 9(1), 98-106.

Lee, N. (2011). Teachers' motivation to integrate technology: A study of expectancy-value, perceived instrumentality, and prosocial goals (Unpublished doctoral dissertation). University Of Oklahoma. Retrieved on 03 June 2018 from Dissertations \& Theses @ University of Oklahoma. (Publication No. 3488211).

Li, B.P. (2012). Analysis for discrepancies in educational technology ability of urban-rural primary and secondary teacher. Modern Educational Technology, 22(4), 29-33.

Li, N. \& Kirkup, G. (2007). Gender and cultural differences in Internet use: A study of China and the UK. Computers \& Education, 48(2), 301-317.

Livingstone, S. \& Helsper, E. (2007). Gradations in digital inclusion: Children, young people and the digital divide. New Media and Society, 9(4), 671-696. 
Lloyd, M. \& Albion, P. (2005, March). Mistaking the tool for the outcome: Using activity system theory to understand the complexity of teacher technophobia. Paper presented at the International Conference of the Society for Information Technology and Teacher Education (SITE). Phoenix, Arizona.

Madhavi, C. \& Vimala, B. (2011). A study on work related stress and work family issues experienced by women software professionals in Chennai. 3rd International Conference on Information and Financial Engineering (IPEDR). Vol.12. Singapore: IACSIT Press.

McCarthy, P.J. (1998). Teacher attitudes toward computers and the relationship between attitudes toward computers and the level of involvement with computers among New York City special education teachers (Unpublished doctoral dissertation). Columbia University Teachers College, New York, DAI 59/01A.

Meraz, S. (2008). Women and technology: How socialization created a gender gap. In P. M. Poindexter, S. Meraz \& A. Schmitz-Weiss (Eds.), Women, men and news: Divided and disconnected in the news media landscape (pp. 99-116). New York: Routledge.

Muralidharan, K., Singh, A., \& Ganimian, A. J. (2017). Disrupting education? Experimental evidence on technology-aided instruction in India. NBER Working Paper No: 22923. Retrieved on 01 October 2017 from https://www.nber.org/papers/w22923.pdf

Nasrin and Islahi, F. (2011). Manual for attitude scale towards information technology for teachers. Agra: Manasvi.

Neyland, E. (2011). Integrating online learning in NSW secondary schools: Three schools perspectives on ICT adoption. Australia Journal of Educational Technology, 27(1),152173

North, A. S. \& Noyes, J. M. (2002). Gender influences on children's computer attitudes and cognitions. Computers in Human Behavior, 18(2), 135-150.

Nunan, D. \& Wong, L. (2005). Innovation and change: Information technology and inservice teacher edu- cation. In C. Davison (Ed.), Information technology and innovation in language education (pp. 195- 227). Hong Kong, China: Hong Kong University Press.

Phelps, R. \& Ellis, A. (2002, July). A metacognitive approach to computer education for teachers: Combining theory and practice for computer capability. Paper presented at the Linking learners: Australian Computers in Education Conference (ACEC 2002), Hobart, Tasmania.

Pinkard, N. (2005). How the perceived masculinity and/or femininity of software applications influences students' software preferences. Journal of Educational Computing Research, 32(1), 57-78.

Plomp, T., Anderson, R. E., Law, N., \& Quale, A. (Eds.). (2009). Cross-national information and communication technology: Policies and practices in education. Charlotte, NC: Information Age.

Potvin, P. \& Hasni, A. (2014). Interest, motivation and attitude towards science and technology at K-12 levels: A systematic review of 12 years of educational research. Studies in Science Education, 50(1), 85-129.

Rajpoot, V.K.S. \& Rajpoot, O. (2011), Attitude of teachers towards educational technology, International Journals of Multidisciplinary Research Academy, 1(1), 40-46.

Rogers, E. M. (1995). Diffusion of innovation (4th ed.). New York: The Free press. 
Romano, M. T. (2003). Empowering teachers with technology. Lanham, MD: Scarecrow Press.

Sainz, M. \& Saez, M. L. (2010). Gender differences in computer attitude and the choice of technology related occupations in a sample of secondary students in Spain. Computers \& Education, 54(2), 578-587.

Sainz, M., Meneses, J., Fabregues, S., and Lopez, B. (2016). Adolescents' gendered portrayals of occupations in the field of information and communication technologies. International Journal of Gender, Science and Technology, 8(2), 181-201.

Salehi, H. \& Salehi, Z. (2012). Integration of ICT in language teaching: Challenges and barriers. Proceedings of the 3rd International Conference on e-Education, e-Business, eManagement and e-Learning (pp.215-219). Hong Kong: IPEDR.

Schottenbauer, M.A., Rodriguesz, B.F., Glass, C.R., \& Arnkoff, D.B. (2004). Computers, anxiety and gender: an analysis of reactions to the $\mathrm{Y} 2 \mathrm{~K}$ computer problem. Computers in Human Behavior, 20(1), 67-83.

Sharma, R. (2013). Teaching attitude of higher secondary schools' teachers of Raebareli. Journal of Indian Research, 1(3), 154-158. Retrieved on 30 July 2017 from http://mujournal.mewaruniversity.in/JIR3/17.pdf

Slaouti, D. \& Barton, A. (2007). Opportunities for practice and development: newly qualified teachers and the use of information and communication technologies in teaching foreign languages in English secondary school contexts. Journal of In-service Education, 33(4), 19.

Tarhini, A., Hone, K. and Liu, X. (2015), A cross-cultural examination of the impact of social, organisational and individual factors on educational technology acceptance between British and Lebanese university students. British Journal of Educational Technology, 46(4), 739-755. doi:10.1111/bjet.12169

Teo, T., Fan, X., \& Du, J. (2015). Technology acceptance among pre-service teachers: Does gender matter? Australasian Journal of Educational Technology, 31(3), 235-251.

Teo, T., Milutinovi C. V., \& Zhou, M. (2016). Modelling Serbian pre-service teachers' attitudes towards computer use: A SEM and MIMIC approach. Computers \& Education, 94(7), 7788.

Terry, A. \& Gomez, R. (2010). Gender and public access computing: An international perspective. The Electronic Journal of Information Systems in Developing Countries, 43(5), 1-17.

Tezci, E. (2009). Teachers' effect on ICT use in education: The Turkey sample. Procedia Social and Behavioral Sciences, 1(1), 1285-1294. http://dx.doi.org/10.1016/j.sbspro.2009. 01.228

Wong, E.M.L. \& Li, S.C. (2008). Framing ICT implementation in a context of educational change: a multilevel analysis. School Effectiveness and School Improvement, 19(1), 99-120.

Wong, S. L. \& Hanafi, A. (2007). Gender differences in attitudes towards information technology among Malaysian student teachers: A case study at Universiti Putra Malaysia. Educational Technology \& Society, 10 (2), 158-169.

Wozney, L., Venkatesh, V., \& Abrami, P.C. (2006). Implementing computer technologies: Teachers' perceptions and practices. Journal of Technology and Teacher Education, 14(1), 173-207. 
Wylie, C (2000). Trends in feminisation of the teaching profession in OECD countries 19801995. ILO Working Paper. Geneva, Switzerland.

Yildirim, S. (2007). Current Utilization of ICT in Turkish basic education schools: A review of teacher's ICT use and barriers to integration. International Journal of Instructional Media, 34(2), 171-86.

Yilmaz, N.P. (2011). Evaluation of the technology integration process in the Turkish education system. Contemporary Educational Technology, 2(1), 37-54.

Yilmaz, R. M. (2016). Educational magic toys developed with augmented reality technology for early childhood education. Computers in Human Behavior, 54, 240-248.

Yusuf, M.O. (2011). Student-teachers' competence and attitude towards information and communication technology: A case study in a Nigerian University. Contemporary Educational Technology, 2(1), 18-36.

Zaman, A., Hussain, M.A., Ghafar A., \& Khan S. (2018). Teachers' conception, attitude and practices of educational technology. Pakistan Journal of Distance and Online Learning, 4(1), 111-122.

Zajonc R.B. (1968). Attitudinal effects of mere exposure. Journal of personality and Social Psychology, 9(2),1-27.

Zhao, Y., Xu, J., \& Chen, M. (2017). Analysis of urban-rural discrepancies in primary and secondary school teachers' ICT application ability in teaching and research in China. Proceedings of the International Symposium on Educational Technology (pp. 131-134). Hong Kong: IEEE. doi: 10.1109/ISET.2017.38

Correspondence: Fatima Islahi, Assistant Professor, Centre for Women's Studies, Aligarh Muslim University, Aligarh, Uttar Pradesh, India 